\title{
Evaluation of mechanical properties and durability performance of HDPE-wood composites
}

Cite as: AIP Conference Proceedings 1664, 150001 (2015); https://doi.org/10.1063/1.4918497 Published Online: 22 May 2015

M. Tazi, F. Erchiqui, H. Kaddami, M. Bouazara, and B. Poaty

\section{ARTICLES YOU MAY BE INTERESTED IN}

Effect of water absorption on the mechanical properties of poly(3-hydroxybutyrate)/ vegetable fiber composites

AIP Conference Proceedings 1664, 060003 (2015); https://doi.org/10.1063/1.4918421

Effects of alkali treatment on the mechanical and thermal properties of Sansevieria trifasciata fiber

AIP Conference Proceedings 1725, 020043 (2016); https://doi.org/10.1063/1.4945497

Development of natural fiber/engineering plastics composites with flame retardance properties

AIP Conference Proceedings 1779, 030020 (2016); https://doi.org/10.1063/1.4965490

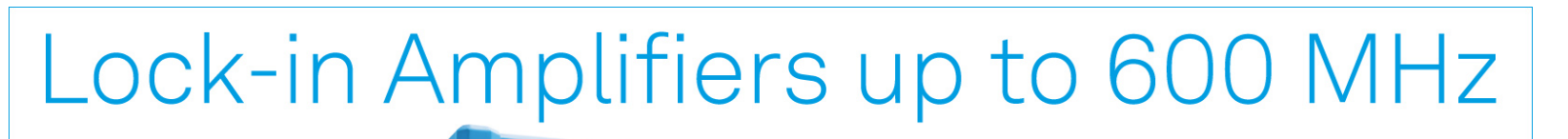

starting at

$\$ 6,210$

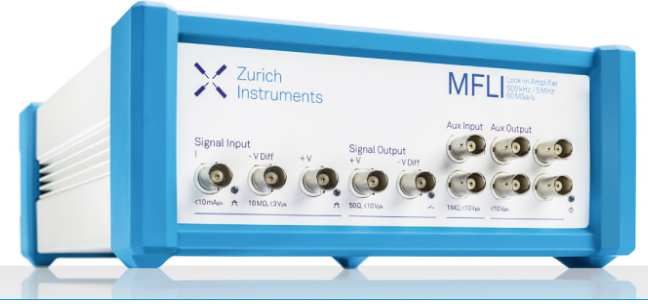




\title{
Evaluation of Mechanical Properties and Durability Performance of HDPE-Wood Composites
}

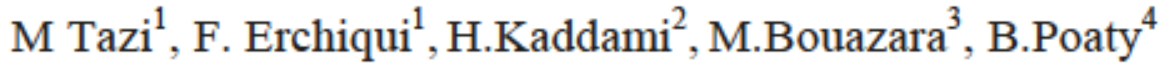 \\ 1 Engineering department, Universite de Quebec en Abitibi-Tëmiscamingue, Canada. \\ 2 Universite Caddi Ayad Marrabech, Laboratoire ICO2MC', B.P. 549, Marrakech 40000, Marroc \\ 3 Mechanical department, Universite de Qübec à Chicoutimi Canada \\ 4 Technology Center of industrial residuals, QC Canada
}

\begin{abstract}
The objective of this work is to evaluate the mechanical properties and durability performance of bio-composite materials made from sawdust and thermoplastic polymer (HDPE). For the preparation of the composites, sawdust in different proportions with Maleic Anhydride grafted Polyethylene (MAPE) as the coupling agent was used. The thermal and mechanical properties were successively characterized. The results indicate that adding wood fillers to a polymer matrix increases the degree of crystallinity and improves the tensile strength and ductility of composites. On the contrary, resistance to water absorption decreases as a function of the wood fillers. Scanning electron microscopy (SEM) was used to analyze morphological structure alteration when exposed to intense weathering. The biodegradability of bio-composites up to 97 days was also investigated; the results indicate that, by increasing the filler content, the amount of weight loss increased as well. In other words, even though the addition of sawdust to thermoplastic polymer improves the mechanical performance of a composite material, it also accelerates the biodegradation rate of the composite. An optimum amount of filler content might compromise the effect of biodegradation and mechanical properties of composite materials
\end{abstract}

Keywords: Wood plastic composites, Mechanical properties, Morphological structure, Biodegradability.

\section{INTRODUCTION}

The mechanical properties of bio-composite materials are highly influenced by the polymeric matrix-wood filler interface. However, incompatibility between the sawdust (hydrophilic) and polymeric matrix (hydrophobic) leads to poor adhesion between the two components, resulting in ineffective mechanical performance $[1,2]$. Many studies have been performed to address this issue, most of them concentrating on the surface modification of natural fibers or use of coupling agents for bonding improvement (hydrogen bonds with the hydroxyl groups of natural fibers) [3, 4]. Even though the additional amount of fiber in a plastic matrix improves the mechanical properties of the composite, it also increases the amount of water absorption, which has a negative effect on the stress transfer between fiber and matrix [5]. It should be noted that hemicelluloses of plant cell walls are responsible for water uptake [6] with the result that fibers with a higher hemicellulose content have a higher moisture absorption and biodegradation. Moisture content also affects the tensile strength, swelling and porosity of fibers [4]. In addition, bio-composites are highly sensitive to micro-organism attack, especially when used in outdoor applications.

As mentioned in the literature, incorporation of sawdust to a polymer matrix appears to influence the durability properties as well as the biodegradation rate of composite materials [7]. The degradation rate of wood differs from one species to another. Such differences are difficult to explain from the chemical composition of the species, as some fungi decompose cellulose or hemicelluloses more rapidly than lignin, while others decompose lignin more efficiently than polysaccharides [8,9]. Toxic content, density of wood species, size of wood particles, and the degree of adhesion between polymer and wood particles are also positive factors in preventing the rapid rate of biodegradation [10]. Application of wood plastic composites in civil engineering is restricted because of their vulnerability to degradation when exposed to moisture. Based on the literature, the addition of a filler to the polymer matrix improves the mechanical strength of composite materials but also increases the sensitivity of composites to environmental elements. Hence, it would be important to estimate how much the mechanical properties of wood plastic composites would be changed by exposing them to intensive environmental conditions.

The effect of the filler content on the mechanical properties, water absorption and biodegradability of wood plastic composites is not sufficiently elucidated in the literature. The purpose of this article, therefore, is to attempt 
to investigate the effect of filler content on the factors mentioned above. The composite material used in this article was composed of high-density polyethylene (HDPE) reinforced with a blend of sawdust (white spruce, black spruce and balsam).

\title{
MATERIALS AND METHODS
}

\begin{abstract}
Materials
The sawdust used in this study was supplied by Tembec sawmill located in Béarn (QC, Canada). It consists of $65 \%$ white spruce (Picea glauca), $20 \%$ of black spruce (Picea marica) and $15 \%$ balsam fir (Abies balsamea). The particle size analysis of the sawdust is performed on more than 5000 particles using the apparatus FQA (Fibre Quality Analyser, Optest Equipement, Hawkesbury Ontario).

The average geometry of sawdust is showed in Table 1. Sawdusts were sieved to diameter less than 700 microns (Ǿ $<0.7 \mathrm{~mm}$ ). The polymeric matrix is high-density polyethylene (Sclair A59), with the melting temperature of $138^{\circ} \mathrm{C}$, and density $980 \mathrm{~kg} / \mathrm{m}^{3}$. The coupling agent is Fusabond $226 \mathrm{DE}$ from Dupont, which is a polyethylene grafted with maleic anhydride (melting temperature of $120^{\circ} \mathrm{C}$, melt flow index (MFI) of $1.5 \mathrm{~g} / 10 \mathrm{~min}$, under condition $190^{\circ} \mathrm{C}, 2.16 \mathrm{~kg}$ ). The used amount of coupling agent is $3 \%$ of total weight of composite. This amount is well known to improve the homogeneity of the mixture ensuring better distribution of fibers in the polymer matrix $[11,12]$.
\end{abstract}

The sieved sawdust was previously dried under temperature of $105^{\circ} \mathrm{C}$ for 24 hours and stored in plastic bags. The moisture content of sawdust was calculated from the mass before and after a second drying (at $120^{\circ} \mathrm{C}$ for 24 hours) and was estimated at less than $3 \%$ by mass.

TABLE 1: Average geometrical dimensions of fillers

\begin{tabular}{cccc}
\hline $\begin{array}{c}\text { Area } \\
{\left[\mathrm{mm}^{2}\right]}\end{array}$ & $\begin{array}{c}\text { Long axis } \\
{[\mathrm{mm}]}\end{array}$ & $\begin{array}{c}\text { Short axis } \\
{[\mathrm{mm}]}\end{array}$ & $\begin{array}{c}\text { Shape ratio } \\
\text { (L/D) }\end{array}$ \\
\hline 0.1154 & 0.52 & 0.30 & 1.97 \\
\hline
\end{tabular}

\section{Methods}

The composite samples were prepared using a co-rotating twin screw extruder (HAAKE) with angular speed of $50 \mathrm{rpm}$ at the temperature of $180^{\circ} \mathrm{C}$. In fact, this temperature is lower than wood fibers degradation temperature $\left(200^{\circ} \mathrm{C}\right)$. In the first step, similar sized wood particles were compounded into pellets at $20 \% \mathrm{wt}, 30 \% \mathrm{wt}, 40 \% \mathrm{wt}$, $50 \%$ wt and $60 \%$ wt by weight of HDPE. In the next step, flat disc samples for biodegradation test and barrette shape samples for water absorption tests were prepared by compression molding using a hot press set at the temperature of $150^{\circ} \mathrm{C}$ (above melting temperature of the polymer, $138^{\circ} \mathrm{C}$ ) with aluminum mold plates.

In order to make sure the mixture is softened properly, a preload was first applied for two minutes. This preload is also beneficial for removing possible accumulated air in the material. Then, loading on the material was continued up to $8 \mathrm{MPa}$ for 4 minutes to give the final shape. The dog-bone samples for tension tests are prepared by injection mold- HAAKE Minijet from thermo scientific. 


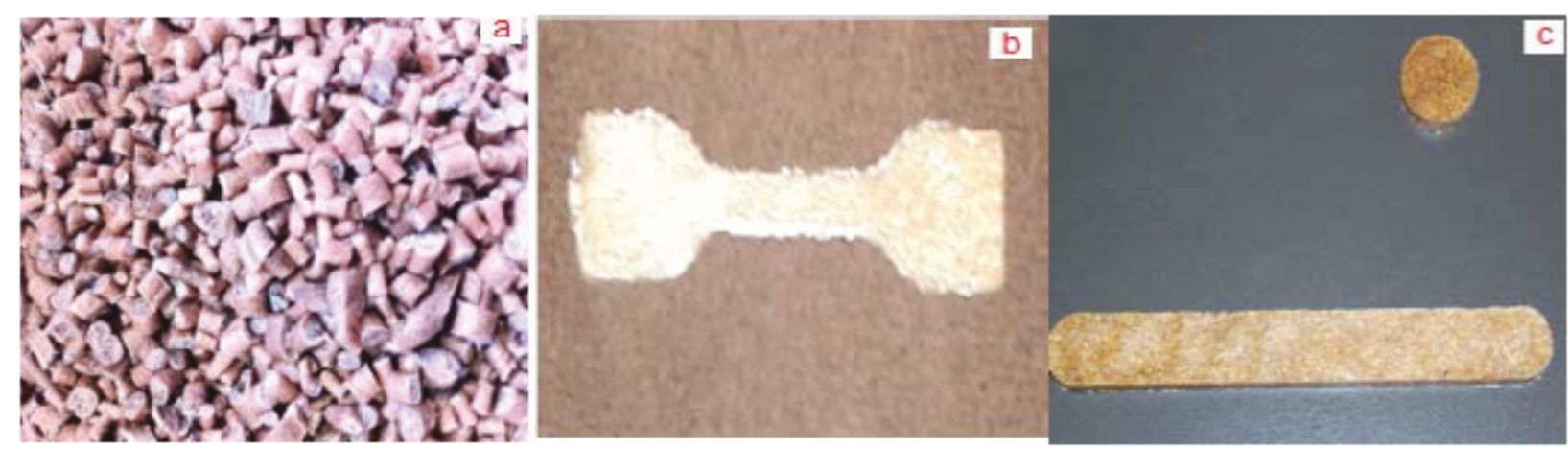

FIGURE 1: Pellets (a), dog-bone samples from injection mold (b), and compression molded samples (c).

\section{RESULTS AND DISCUSSION}

\section{Tensile tests}

Results of tensile tests demonstrate the effects of the wood content and the coupling agent respectively on the tensile properties of the composites. In all the samples, the modulus increases with the increase in the wood flour content. However, this increase was more predominant in samples with a coupling agent, which was in fact expected because of the higher modulus of wood fillers. By contrast, as mentioned in several studies, the mechanical strength of bio-composites without a coupling agent will be decreased by adding wood fillers because of stress concentration at the edge of the fillers [11]. Addition of a coupling agent makes for a significant improvement in the mechanical properties of composite materials because of a better adhesion and improved stress transfer between fiber and matrix. As a result, the tensile strength will be increased by the addition of wood fillers [12].

In comparison to neat HDPE, the tensile strength of a composite with $3 \%$ coupling agent was improved by $13 \%, 34 \%$ and $54 \%$ respectively when $20 \% 30 \%$ and $40 \%$ wood fillers were added to the polymer matrix [Table 2 ]. Increasing the filler content leads to a considerable increase in tensile strength, which can be attributed to the intrinsic adhesion of the filler -matrix interface caused by the chemical modification of the coupling agent (MAPE). As the wood content increases, more particles are available per unit cross-section area of the composite; hence, the stress at break increases [4]. Certain authors reported that manufacturing composites by injection mold with a coupling agent is more effective in mechanical properties [13]. In fact, composite materials prepared by injection are more compact and free from voids. However, at high filler content, shaping the composite by injection is more difficult and thermo-compression method could be more appropriate.

\section{Biodegradability tests}

The effect of fungi species G.trabeum on wood degradation as a function of the wood content and coupling agent was investigated. The fungal attack was more obvious in the case of composite with high wood fillers content and without a coupling agent. The presence of coupling agent reduces greatly the weight loss for the composite material. Indeed, weigh lost was estimated 45 times less for composite made with $40 \%$ wt wood filler when $3 \%$ wt of coupling agent has been added to mixture. Also, the weight loss of composites made with different concentrations of wood ( $0 \%$ wt, $20 \%$ wt, $30 \%$ wt and $40 \%$ wt) and with $3 \%$ of MAPE agent for up to 97 days has been studied. In all cases, the weight loss was considered low, and equal respectively to 0 , $0,82 \%, 0,93 \%$ and $0,97 \%$.

While there was no micro-organism effect on the neat matrix, an attack by micro-organisms on wood fillers would be the only reason for this weight loss. This could be attributed to the moisture effect, which can accelerate the biodegradation mechanism. The fibers are sensitive to water absorption so the uptake of more water in the composite material results in more dimension changes in the polymer matrix, leading to cracking and fissuring of the polymer surface. Thus, fungal species can reach the wood fillers through such discontinuities. Some authors report that scanning electron microscopy of wood-plastic composite specimens confirms the growth of fungal mycelium, which is concentrated in discontinuities between the wood fillers and thermoplastic component near the specimen surface [15].

Composite with high content of wood filler are more susceptible to absorb a large amount of water, which makes them more degradable, when in contact with microorganism. Also, composites without a coupling agent show the maximum percentage of 
water absorbed by wood fillers resulting in a higher weight loss when exposed to fungi decay. This result is in accordance with the dimension change of composite materials [16]. Water uptake produces cracks in the surface of a composite, presenting wood to the environment and making it accessible to fungal attack. As time passes, such cracks increase, resulting in further degradation of the composite. It should be noted that this degradation is promoted by a high content of wood filler and, also, by the weakness of the chemical interaction between wood particles and polymer chains. Meanwhile, a high content of HDPE and use of a coupling agent minimize a susceptibility to weight loss during the accelerated decay test. Investigation of the structural alteration and changes in the surface chemistry of a composite can lead to a better understanding of the degradation mechanism.

\section{Morphological structures analysis}

Scanning electron micrographs (SEMs) of samples with $40 \%$ of wood filler with and without a coupling agent that had been exposed to fungi attack were analyzed. Examination of the composite surface was performed. SEM observation provides information about how a microbial attack can affect the morphological structure of the composite surface and how an additive can prevent drastic degradation of the morphological structure of composites.

Firstly, the decay manifested in a surface composite in the form of surface erosion Figure 2 . The limited number of wood particles exposed on the surface would degrade when exposed to the fungi. If pathways into the specimen existed, the mycelium would propagate further. This decay mechanism is similar to that observed for the microbial degradation of polyethylene-starch composites [15]. Figure 2 show the deterioration of composite samples exposed to fungi attack when compared to a control sample. Substantial deterioration is observed for composites made without a coupling agent. In fact, poor adhesion between fiber particles and polymer matrix generates void spaces around the fibers, enhancing water immersion in the matrix polymer, which causes more cracks and scission of polymer molecule chains [16].

Effective adhesion between wood fibers and polymer enhances the resistivity of the composite to moisture which in turn prevents the degradation of bio composites. The wood particles were impregnated by the polymer matrix, which plays a barrier against water and organic substances. However, possible diffusion of the water to composite can enhance the role of microbial attack by worsening the fiber-matrix adhesion. Hence, concentration of the stress at the edges of the fibers can decrease the mechanical strength of the composite. Furthermore, detachment of fiber and matrix can occur based on the results of this study. [16]. The effect of the fungal attack is greater in the case of a composite without MAPE. In fact, in this case, the fibers tend to agglomerate, making it easier for the diffusion of water and also the organic species through the cavities of the wood fibers, resulting in a rapid degradation of the composite.

\section{CONCLUSION}

We studied the mechanical and structural properties of bio-composites made from high-density polyethylene reinforced with different levels of sawdust in the presence of a coupling agent. The alteration of the structural properties of the bio-composites and the resistance to microbial attack and water absorption were also examined. Our results indicate that the addition of sawdust improves the mechanical properties of bio-composites. It allows a considerable increase in both modulus and strength tensile, although the composite becomes more vulnerable to moisture uptake and susceptible to micro-organism attacks. An optimized amount of fiber content could alleviate the composite degradation process as a result of the decomposition of wood fillers.

\section{FUNDING SUPPORT}

This work was supported by the 'Fond Québécois de la recherché sur la Nature et les technologies (FQNRT)'; the Natural Sciences and engineering Research Council of Canada (NSERC); Centre Technologique des Résidus industriels (CTRI) 


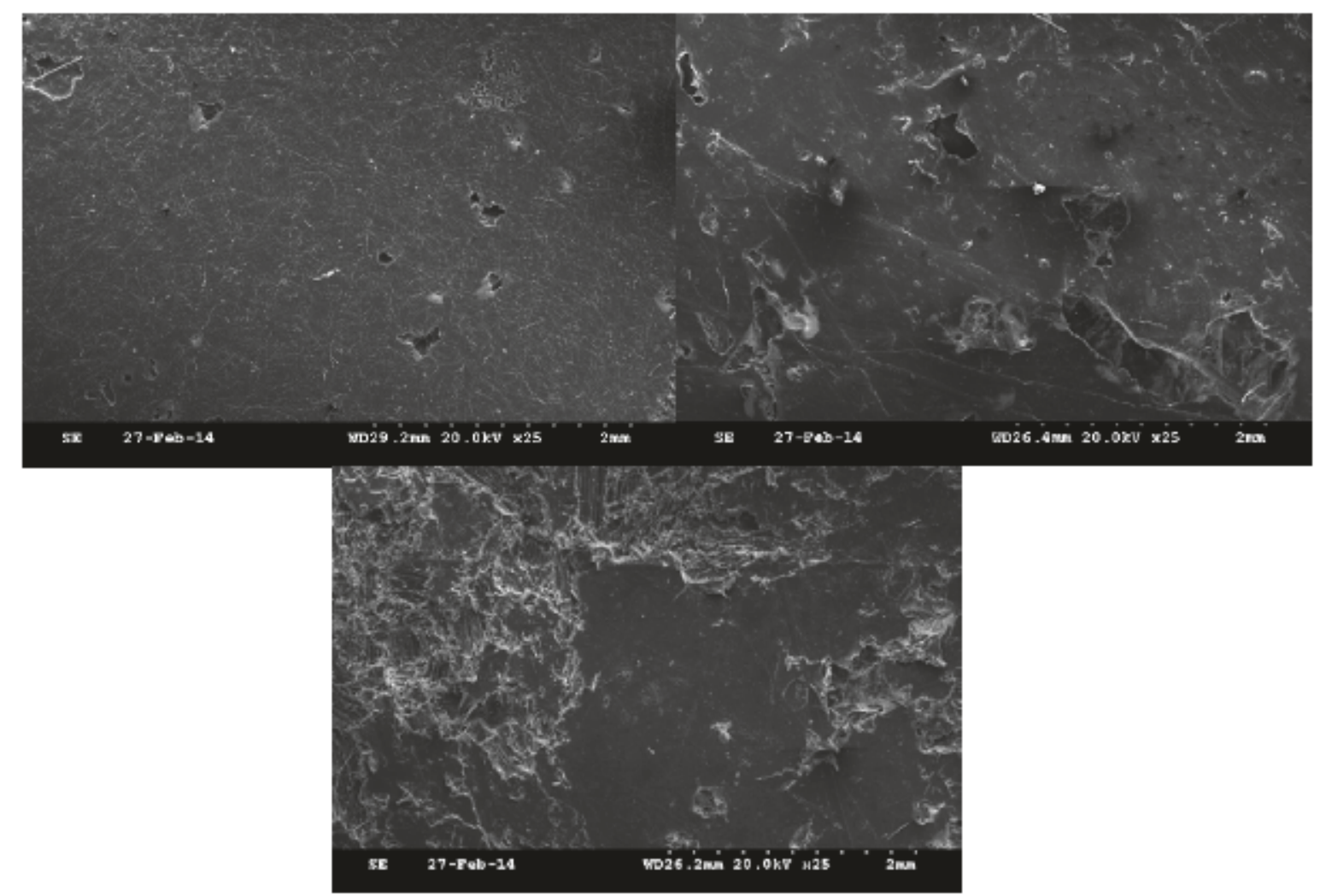

FIGURE 2. Surface analyzes of composite made of HDPE- $40 \%$ wood (a) control sample (b) HDPE- $40 \%$ wood with MAPE (c) HDPE- $40 \%$ wood without MAPE exposed to microorganism attack up to 97 days

\section{REFERENCES}

1. Beldzki, A.K., V.E. Sperber, O. Faruk, and ebrary Inc., Natural and wood fibre reinforcement in polymers 2002 , Shawbury, U.K.: Rapra Technology Ltd. (1 texte électronique)144 p.

2. Bledzki, A.K., O. Faruk, and M. Huque, Polymer-Plastics Technology and Engineering, 2002. 41(3): p. 435-451.

3. Bledzki, A.K., S. Reihmane, and J. Gassan, Polymer-Plastics Technology and Engineering, 1998. 37(4): p. 451-468.

4. Wei, L., A.G. McDonald, C. Freitag, and J.J. Morrell, Polymer Degradation and Stability, 2013.

5. Beg, M.D.H. and K.L. Pickering, Polymer Degradation and Stability, 2008. 93(10): p. 1939-1946.

6. Azwa, Z., B. Yousif, A. Manalo, and W. Karunasena, Materials \& Design, 2012.

7. López Naranjo, E.J., L.M. Alzate Gaviria, G. Hernández Zárate, J. ReyesTrujeque, C.V. Cupul Manzano, and R.H. Cruz Estrada, Joumal of applied polymer science, 2012.

8. Manfredi, L.B., E.S. Rodríguez, M. Wladyka-Przybylak, and A. Vázquez, Polymer Degradation and Stability, 2006. 91(2): p. 255-261.

9. Idicula, M., A. Boudenne, L. Umadevi, L. Ibos, Y. Candau, and S. Thomas, Composites Science and Technology, 2006. 66(15): p. 2719-2725.

10. Wong, K, B. Yousif, and K. Low, Proceedings of the Institution of Mechanical Engineers, Part L: Journal of Materials Design and Applications, 2010. 224(3): p. 139-148.

11. Godard, F., M. Vincent, J.F. Agassant, and B. Vergnes, Journal of Applied Polymer Science, 2009. 112(4): p. 2559-2566.

12. Puglia, D., J. Biagiotti, and J. Kenny, Joumal of Natural Fibers, 2005. 1(3): p. 23-65.

13. Migneault, S., A. Koubaa, F. Erchiqui, A. Chaala, K. Englund, and M.P. Wolcott, Composites Part A: Applied Science and Manufacturing, 2009. 40(1): p. 80-85.

14. Bendahou, A., H. Kaddami, H. Sautereau, M. Raihane, F. Erchiqui, and A. Dufresne, Macromolecular Materials and Engineering, 2008. 293(2): p. 140-148.

15. Pendleton, D.E., T.A. Hoffard, T. Adcock, B. Woodward, and M.P. Wolcott, Forest Products Journal, 2002. 52(6): p. 21-27.

16. Tazi, M; Erchiqui, F; Kaddami, H; and Poaty,b; Biodegradability and mechanical performance of wood-HDPE composites, in process. 